\title{
MOISTURE HUMIDITY EQUILIBRIUM OF WOOD CHIPS FROM ENERGETIC CROPS
}

\author{
Jan Barwicki, Wiesław Golka
}

\section{Introduction}

Prices of traditional energetic fuels are very high and it looks that they will grow in the future. It is connected with limited amount of their resources and non profitable way of extraction. Poland belongs to EU and we have defined strategic obligations concerning energetic planning for the future. Renewable energy sources as a part of total national energy demand in Poland will be equal 7.5 percent in the year 2010 and 14 percent in the year 2020. Actual value of renewable energy sources is equal 3 percent. Biomass takes the leading role in between the energetic fuels. It can be obtained from forest, furniture manufacturers and garden bushes residuals. Additional amount of biomass energetic market supply is fast growing cultivation of energetic willow. The largest cultivations of willow for energetic purposes are located in Sweden and takes about 17000 hectares. Actual area of cultivations of energetic willow in Poland is equal about 2000 hectares. Comparison of energetic values of different energetic fuels is presented in table 1.

Energetic willow is characterized four times higher yield of wood per year compare to typical natural growing trees in forest area. Besides that from one hectare of cultivation it can be obtained from 30 to 40 tons of wooden material. Additionally this plant has low requirements concerning soil type, lower level of fertilizer use and high resistance to strong climatic conditions, presence of diseases and insects. Wooden wastes and material from energetic willow can be stored in the form of wood chips at high moisture content i. e. about 50 percent of dry matter.

\section{Description of experimental apparatus}

Storage of woodchips is connected with possibilities of temperature growth of the material, its degradation and development of harmful bacteria what finally leads to dry matter losses. To avoid that it is important to know the characteristic of fundamental parameters i.e. dependence between moisture content of wooden material during storage and air relative humidity when changing environment temperature. These data is very important from the point of view of controlling storage processes, drying processes and evaluation of energetic value of biological hygroscopic materials as

\begin{tabular}{|c|c|c|c|}
\hline Type of fuel & Energetic value $(\mathrm{GJ} / \mathrm{t})$ & Price $\left(\mathrm{PLN}^{1} / \mathrm{t}\right)$ & Price of $1 \mathrm{GJ}$ of energy $\left(\mathrm{PLN}^{1} / \mathrm{GJ}\right)$ \\
\hline Fuel oil & 43 & 2800 & 65.1 \\
\hline Coal & 26 & 320 & 12.3 \\
\hline Fine coal & 21 & 210 & 10.0 \\
\hline Natural gas $\left(\mathrm{GJ} / 1000 \mathrm{~m}^{3}\right)$ & 38 & 1000 & 26.3 \\
\hline Energetic willow - dry matter & 20 & 25 & 1.25 \\
\hline
\end{tabular}

TABLE 1 - Energetic value of typical fuels.

Paper received 27.06.2007; accepted 29.07.2008

Dr J. BARWICKI, Agency for Restructuring and Modernization of Agriculture (ARMA) Warsaw, Poland, Postdoctoral studies in the Institute for Buildings, Mechanization and Electrification of Agriculture (IBMER) Warsaw, Poland. Dr W. GolKA, Institute for Buildings, Mechanization and Electrification of Agriculture (IBMER), Warsaw, Poland.

$1 \quad$ PLN $=0.31 €$ wood, stalk from field cultivations, grain. For more precise evaluation of the process it is necessary to provide tests on laboratory scale to obtain proper relationships for real conditions. During tests of equilibrium conditions of biological hygroscopic materials and relative humidity of surrounding air [3] it was proved that, air temperature changes in the range of $10^{\circ} \mathrm{C}$ doesn't have substantial influence for keeping of equi- 
librium state. However research provided [2, 4] and taking into account wider ranges of temperature, proved evident influence for equilibrium state of the material and relative humidity of surrounding air. However [7] when testing isotherms of equilibrium state for twenty different types of grains regularly used for agricultural cultivations have proved, that to obtain constant equilibrium of air relative humidity and changing moisture content of the material is more difficult and requires more time than obtaining constant equilibrium moisture content of testing sample when changing relative humidity of air. Woodchips in the sense of hygroscopic biological characteristic are very similar to grain obtained from field cultivations. In spite of this while providing research of equilibrium state of important parameters of that process for their storage it can be utilized certain analogy. Provided tests [5, 6] accomplished evaluation of equilibrium of moisture content and relative humidity of surrounding air using the following equation

$$
\Phi=1-\exp \left[-\mathrm{K}(\mathrm{T}+\mathrm{C})(100 \mathrm{~W})^{\mathrm{N}}\right]
$$

Evaluation of similar dependence for equilibrium state of wood chips could make possibility of construction of the model equilibrium state allowing providing computer simulation for different storage conditions of wooden materials, which are a potential source for energetic or furniture industry purposes. It is possible to solve this problem by providing proper experiments. The best way to do this is provide experiment relaying on bringing small amount of air to equilibrium with relative big sample of woodchips. Experimental rig to provide such research study is presented schematically on Fig. 1.

Sample of Sitka Spruce whole tree is placed in a glass container (2) at volume of $0.5 \mathrm{dm}^{3}$ and put into isolated water bath (1), where it is possible to set dif-

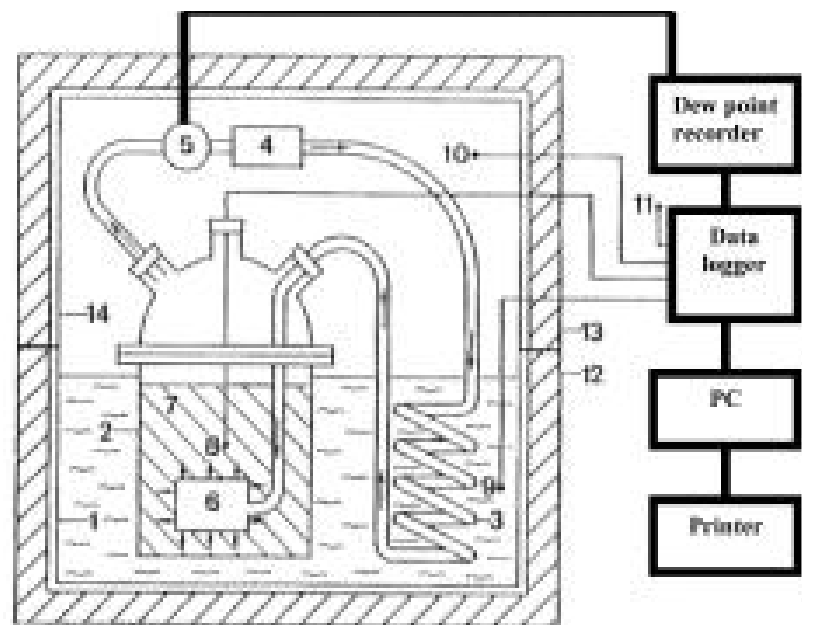

Fig. 1 - Scheme of experimental rig for testing of equilibrium moisture content of wood chips and relative humidity of surrounding air: 1 - water bath, 2 - glass container, 3 - heat exchanger, 4 - air pump, 5 - dew point temperature sensor, 6 - air distributor, 7 - wood chips, 8,9,10,11 - sensors, 12 - lower isolation, 13 - upper isolation. ferent temperatures. In water bath (1) is placed also spiral heat exchanger (3). Pump (4) at a capacity of $0,88 \mathrm{dm}^{3} / \mathrm{min}$ is pumping air to the spiral heat exchanger (3) and then to air distributor (6). Air at a constant temperature equal to water bath (1) temperature is passing through a sample of woodchips (7). While providing tests each sample of woodchips have different moisture content. Air after passing a sample of woodchips is going through dew point temperature sensor (5). All test parameters are recorded by data logger and they are as follows: water bath temperature (9), woodchips temperature (8), temperature under cover (10), environment temperature (11), dew point temperature and relative humidity of air passing through the woodchips. A testing rig allows to move small amount of air in a closed circuit, from spiral (3), which works as a heat exchanger through a sample of woodchips and then to the dew point recorder (5).

Time to obtain by hygroscopic material an equilibrium state in case of constant moisture content of sample is equal from 5 to 10 hours. However relative humidity of surrounding air and changing moisture content of the sample can reach equilibrium state during a few month [1]. Preparation of samples at definite but different moisture content of the material is very important role in this case. Relative humidity of air which is moving in a closed circuit of experimental rig can be calculated by using dew point temperature and sample temperature.

\section{Results of investigations}

A pressure of saturated vapor at a proper temperature of sample and proper dew point temperature, taking into account research done [6], can be calculated from the following equation

$$
\mathrm{P}=\mathrm{a}_{\mathrm{o}}+\mathrm{a}_{1} \mathrm{~T}+\mathrm{a}_{2} \mathrm{~T}^{2}+\mathrm{a}_{3} \mathrm{~T}^{3}+\mathrm{a}_{4} \mathrm{~T}^{4}+\mathrm{a}_{5} \mathrm{~T}^{5}+\mathrm{a}_{6} \mathrm{~T}^{6}
$$

Air temperature and relative humidity changes in time of Sitka Spruce whole tree at moisture content of 14.5 percent is presented on Fig. 2. Nevertheless sample temperature changes during the experiment, its relative humidity stayed at the same level.

However on Fig. 3 it is presented dependence of sample temperature at moisture content of 14.5 percent from relative humidity of surrounding air. From the graph results, that when sample temperature is growing, relative humidity of surrounding air is growing also.

Obtained of experiment results were compared to isotherms made using modified Henderson equation of the following form

$$
\Phi=100\left\{1-\exp \left[(-\mathrm{B}+\mathrm{T}) \mathrm{M}^{\mathrm{C}}\right]\right\}
$$

As it was presented on Fig. 4, when the value of air relative humidity can reach value of 90 percent, we can see an affect of rapid grows of moisture content of wooden material. 


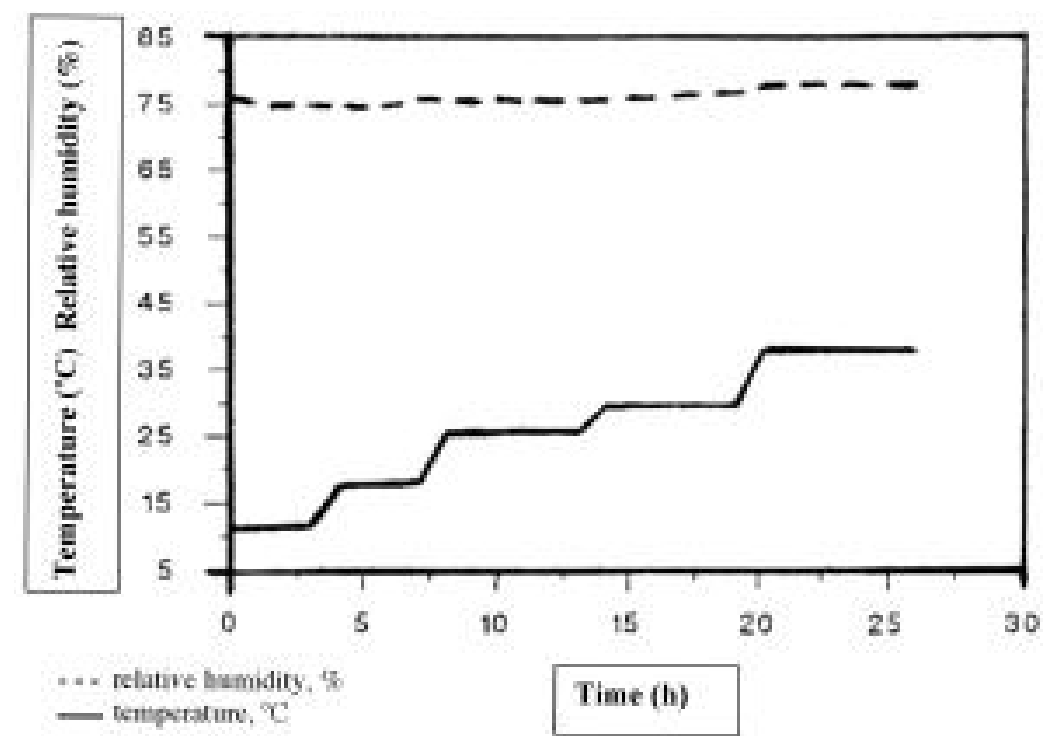

Fig. 2 - Air temperature and relative humidity changes of wood chips of Sitka Spruce whole tree at moisture content of $14.5 \%$.

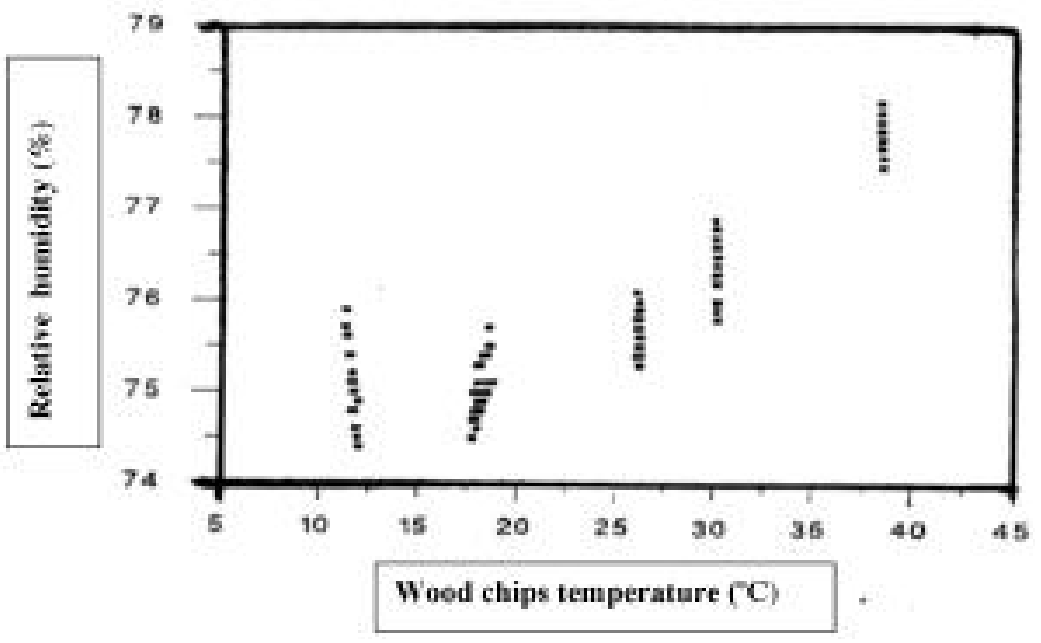

Fig. 3 - Dependence of air temperature from relative humidity of wood chips with Sitka spruce whole tree at moisture content of $14.5 \%$.

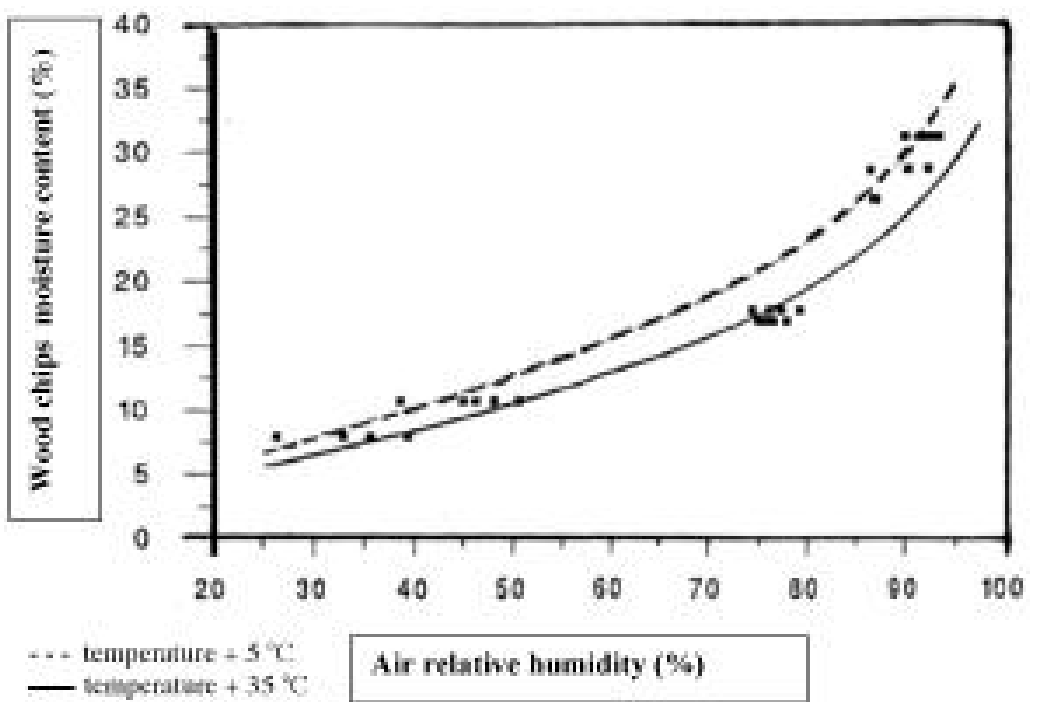

Fig. 4 - Dependence of moisture content of wood chips from relative moisture content of Sitka Spruce whole tree. 
From the experiments results, that modified Henderson equation can be utilized for simulation processes of storage and drying of woodchips, because it describes the characteristic of the material presented during the tests of above research. Besides that presented dependences are very similar to those described in other papers concerned behavior in different environment conditions other hygroscopic biological materials.

\section{Conclusions}

To avoid dry matter losses of wooden materials during their storage, it is important to know fundamental characteristic of parameters of existed processes but especially: moisture content of the material, relative humidity and temperatures of the environment.

Presented research shows, that when relative humidity of air reaches about 90 percent, than it can be observed rapid grows of moisture content of stored woodchips.

Provided experiments results showed, that modified Henderson equation can be utilized for simulation of the processes for storage and drying of woodchips.

Evaluated modified Henderson equation allows to built a mathematical model for providing computer simulation of different storage conditions of woodchips for energetic and furniture purposes.

\section{References}

[1] BARWICKI J. (1992). Moisture humidity equilibrium for Sitka Spruce whole tree. (Unpublished). Silsoe Research Institute, England.

[2] BRoOKer D.B., BAKKeR-ArKema F.W. (1988). The AVI Publishing Co. Inc. Westport.

[3] Coleman D.A., Fellows H.C. (1995). Hydrostatic moisture of cereal grains and flaxseed exposed to atmospheres different relative humidity. Cereal Chemistry No 2.

[4] HaLl C.W. (1957). Drying farm crops. Edwards Brothers Inc.

[5] Henderson S.M. (1992). A basic concept of equilibrium moisture content of cereal grains. Agriculture Engineering.
[6] Love P.R. (1988). An approximation polynomial for the computation of saturation vapour pressure. Journal of Applied Meteorology No 16.

[7] RaO V.G., Pfost H.B. (1984). Physical properties related to drying 20 food grains. ASAE 80-3539.

\section{SUMMARY}

Processes occurring during storage of wood chips for energetic or furniture industry purposes were presented. As a result of carried out investigations, dependences of temperature and relative humidity changes of surrounding air were shown. Modified Henderson equation can be utilized for computer simulation of storing and drying processes concerning wood chips for energetic and furniture industry purposes. It reflects also obtained results from experiments carried out with above mentioned material. Using computer simulation program we can examine different wood chips storing conditions to avoid overheating and loss problems.

\section{Key words:}

energetic plants, forest wastes, biomass, storing, utilization, energy, furniture, moisture content, relative humidity.

\section{List of symbols}

$\begin{array}{ll}\mathbf{a}_{\mathbf{0}} & 6.1077 \mathrm{kPa} \\ \mathbf{a}_{\mathbf{1}} & 4.4365 \times 10^{-1} \mathrm{kPa}\left({ }^{\circ} \mathrm{C}\right)^{-1} \\ \mathbf{a}_{\mathbf{2}} & 1.4289 \times 10^{-2} \mathrm{kPa}\left({ }^{\circ} \mathrm{C}\right)^{-2} \\ \mathbf{a}_{3} & 2.6550 \times 10^{-4} \mathrm{kPa}\left({ }^{\circ} \mathrm{C}\right)^{-3} \\ \mathbf{a}_{\mathbf{4}} & 3.0312 \times 10^{-6} \mathrm{kPa}\left({ }^{\circ} \mathrm{C}\right)^{-4} \\ \mathbf{a}_{\mathbf{5}} & 2.0340 \times 10^{-8} \mathrm{kPa}\left({ }^{\circ} \mathrm{C}\right)^{-5} \\ \mathbf{a}_{\mathbf{6}} & 6.1368 \times 10^{-11} \mathrm{kPa}\left({ }^{\circ} \mathrm{C}\right)^{-6} \\ \mathrm{~B}, \mathrm{C} & \text { constant } \\ \mathrm{K} & \text { equal to 1 } \\ \mathrm{M} & \text { dry matter content, } \% \\ \mathrm{~N} & \text { exponent related to the type of grain } \\ \mathrm{P} & \text { pressure of saturated vapor, Kpa } \\ \mathrm{T} & \text { temperature, }{ }^{\circ} \mathrm{C} \\ \mathrm{W} & \text { grain moisture content, \% } \\ \Phi & \text { air relative humidity, \% }\end{array}$

